\title{
THE NATURE OF FLOW IN THE SYSTEMIC VENOUS PATHWAY MEASURED BY MAGNETIC RESONANCE BLOOD TAGGING IN PATIENTS HAVING THE FONTAN OPERATION
}

Mark A. Fogel, MD, FACC ${ }^{\text {a,c }}$ Paul M. Weinberg, MD, FACC Alison Hoydu, $\mathrm{PhD}^{\mathrm{c}}$

Anne Hubbard, $\mathrm{MD}^{\mathrm{c}}$

Jack Rychik, MD, FACC

Marshall Jacobs, $\mathrm{MD}^{\mathrm{b}}$

Kenneth E. Fellows, $\mathrm{MD}^{\mathrm{c}}$

John Haselgrove, $\mathrm{PhD}^{\mathrm{c}}$
Objectives: Our objectives were twofold: (1) to determine cardiac and respiratory dependency of systemic venous pathway flow of patients having the Fontan operation with a total cavopulmonary connection and (2) to describe the velocity profile. Systemic venous pathway flow is hypothesized to be mostly respiratory dependent, to be laminar, and to have a smooth velocity profile. Methods: Twenty-two patients having the Fontan operation (aged 8.6 \pm 4.7 years) underwent magnetic resonance blood tagging (bolus tagging). Systemic venous pathway spin-echo images parallel to the blood flow were used as a localizer. A saturation pulse labeled the blood, and a cine image was acquired at the inferior and superior venae cavae and midportion of the baffle in the systemic venous pathway, triggered to the electrocardiogram and gated to both end-expiration and end-inspiration. Repetition time was 50 msec. Results: Flow in the systemic venous pathway was laminar throughout its course and was found to be phasic to both cardiac and respiratory cycles. Approximately $70 \%$ of flow was cardiac dependent, and the rest was respiratory. Highest flow occurred near end-systole and early diastole and in inspiration. Lowest flow occurred in diastasis. Velocity was highest and flow least "pluglike" in the mid-baffle area during cardiac or respiratory imaging $(45 \pm 17$ and $32 \pm 11 \mathrm{~cm} / \mathrm{sec}$, respectively). Conclusion: A substantial amount of pulmonary blood flow in patients who have undergone a total cavopulmonary connection type of Fontan operation has a cardiac component. Furthermore, we confirm that this flow is laminar but nonuniform across the systemic venous pathway. Highest flows occurred near end-systole and early diastole, as well as in inspiration, and the lowest flow occurred in diastasis. This information may help in designing the systemic venous pathway and optimizing medical management. (J Thorac Cardiovasc Surg 1997;114:1032-41)
$T^{1}$ he driving force behind blood movement into the pulmonary circulation in the absence of a pumping chamber is not completely understood. ${ }^{1-14}$ It is a combination of negative intrathoracic pressure during inspiration and of contraction and motion of the systemic ventricle. ${ }^{1-3,5-11}$ Respiration is thought to be a major component. ${ }^{2,3,8,12-14}$

Whatever the mechanism, the optimal way to channel blood from the inferior vena cava (IVC) to

From the Division of Cardiology, Department of Pediatrics, ${ }^{a}$ the Division of Cardiothoracic Surgery, Department of Surgery, ${ }^{b}$ and the Department of Radiology, ${ }^{\mathbf{c}}$ The Children's Hospital of Philadelphia, and the Departments of Pediatrics, Surgery, and Radiology, The University of Pennsylvania School of Medicine, Philadelphia, $\mathrm{Pa}$.

Dr. Fogel has been funded through a fellowship grant of the Southeastern Pennsylvania affiliate of the American Heart Association. the pulmonary arteries ${ }^{15,16}$ has also received much attention, although it is thought that energy efficiency is achieved by the cylindric baffle concept. ${ }^{15}$

This study enlists a magnetic resonance blood tagging technique called bolus tagging ${ }^{17-19}$ to visualize flow patterns across the diameter of the systemic venous pathway (SVP). We address, in vivo, the issue of cardiac versus respiratory dependency of SVP flow and describe the velocity profiles in the

Received for publication ov. 21, 1996; revisions requested Jan. 6, 1997; revisions received June 12, 1997; accepted for publication June 12, 1997.

Address for reprints: Mark A. Fogel, MD, Wyeth-Ayerst Research, Cardiovascular Division, C-2, 145 King of Prussia Rd., Radnor, PA 19087.

Copyright $(\mathcal{C} 1997$ by Mosby-Year Book, Inc.

$0022-5223 / 97 \$ 5.00+0 \quad \mathbf{1 2 / 1 / 8 4 3 0 4}$ 
"energy efficient" cylindric baffle to gain some concept of the nature of this flow.

\section{Methods}

Patients. We prospectively studied 22 patients with functional single ventricle who underwent Fontan reconstruction at The Children's Hospital of Philadelphia between June 1994 and July 1995. Patients ages were $8.6 \pm$ 4.7 years, time from operation was $4.1 \pm 4.9$ years, and age at operation was $2.7 \pm 2.1$ years. Anatomic diagnoses are listed in Table I. Seven patients had small baffle fenestrations although all patients had aortic oxygen saturations greater than $90 \%$. This implied little hemodynamic significance. Patients were in stable enough condition to undergo a 1-hour magnetic resonance imaging (MRI) study while sedated. All patients underwent echocardiography within 6 months of MRI and had qualitatively good ventricular shortening. No patients had symptoms referable to the cardiovascular system or had venous pathway obstruction. Informed consent was obtained from all participants. All patients had normal sinus rhythm and no arrhythmias. All MRI studies were adequate for interpretation.

All patients underwent a total cavopulmonary connection by creation of a tunnel at the lateral atrial wall. This consisted of a hemicylindric polytetrafluoroethylene tube graft* sewn into the lateral and posterior atrial walls, creating a circular channel for blood to flow from the IVC to an anastomosis between the superior vena cava (SVC) and right pulmonary artery.

MRI. Studies were performed on a Siemens 1.5-tesla Magnetom SP 63 device (Siemens Corp., Union, N.J.). A respiratory bellows and electrocardiographic (ECG) leads were placed in each subject. If less than 7 years old, the patient was given either chloral hydrate 75 to $120 \mathrm{mg} / \mathrm{kg}$ (if $<2$ years) or pentobarbital (Nembutal) 2 to $6 \mathrm{mg} / \mathrm{kg}$ intravenously.

Scanning protocol was as follows (Fig. 1A):

1. After coronal localizers, ECG-triggered T1-weighted transverse images were acquired, spanning the entire thorax which were used as localizers for subsequent magnetic tagging. A series of T1-weighted oblique sagittal images were acquired to obtain images along the long axis of the SVP (Figs. 1A and 1B). These images ensured that the final blood tagging sequence was performed in the center of the vessel.

2. Multiple prospectively triggered and gated bolus tagging images ${ }^{17-19}$ were then acquired (Figs. 1A and 1B). This gradient echo sequence uses radiofrequency pulses to produce saturated spins along a line designated by the user (a black stripe on the image) where each acquisition was preceded by a saturation pulse. The movement of blood displaces the saturation band, whereas stationary structures (e.g., chest wall and spine) maintain the saturation band's original position. Saturation band displacement on blood relative to the chest wall and spine allows for velocity and flow calculation (Fig. 1A). Each image represents blood displacement between tagging and image

\footnotetext{
* Gore-Tex graft, registered trademark of W. L. Gore \& Associates, Inc., Elkton, Md.
}

Table I. Breakdown of patients by anatomic diagnosis

\begin{tabular}{|c|c|}
\hline $\begin{array}{l}\text { Patient } \\
\text { No. }\end{array}$ & Diagnosis \\
\hline 1 & $\begin{array}{l}\text { RV Ao with PA }\{\mathrm{S}, \mathrm{L}, \mathrm{X}\}, \mathrm{RAVV} \text { atresia, } \\
\text { hypoplastic LV }\end{array}$ \\
\hline 2 & HLHS \\
\hline 3 & DORV, single RV, PS \\
\hline 4 & DILV, PS \\
\hline 5 & HLHS \\
\hline 6 & $\begin{array}{l}\text { SI-Vent, DORV }\{S, L, D\}, \text { CCAVC malaligned to } \\
\text { LV, PS }\end{array}$ \\
\hline 7 & DORV $\{\mathrm{S}, \mathrm{D}, \mathrm{D}\}, \mathrm{MA}, \mathrm{TAPVC}$ to LSVC \\
\hline 8 & HLHS \\
\hline 9 & HLHS \\
\hline 10 & TGA $\{$ S,L,L $\}$, DILV, LAVV hypoplasia \\
\hline 11 & DORV $\{\mathrm{S}, \mathrm{D}, \mathrm{L}\}$, single $\mathrm{RV}, \mathrm{PS}$ \\
\hline 12 & $\begin{array}{l}\text { DORV }\{\mathrm{S}, \mathrm{D}, \mathrm{D}\} \text {, malalignment VSD, PS, subAS with } \\
\text { arch hypoplasia, straddling mitral valve }\end{array}$ \\
\hline 13 & DORV $\{A, D, D\}, C C A V C$ \\
\hline 14 & DORV $\{\mathrm{S}, \mathrm{D}, \mathrm{D}\}$, single $\mathrm{RV}$, subAS \\
\hline 15 & TA, TGA $\{S, D, D\}$, IAA type A \\
\hline 16 & TGA $\{S, L, L\}, D I L V$ \\
\hline 17 & DORV $\{\mathrm{S}, \mathrm{D}, \mathrm{D}\}, \mathrm{MA}, \mathrm{AS}$ \\
\hline 18 & HLHS \\
\hline 19 & HLHS \\
\hline 20 & HLHS \\
\hline 21 & HLHS \\
\hline 22 & $\begin{array}{l}\text { DORV }\{\text { S,L,D }\} \text {, SI-Vent, canal + malalignment } \\
\text { VSDs, straddling TV }\end{array}$ \\
\hline
\end{tabular}

$\{A, D, D\}$, Situs ambiguus of the atria, D-loop ventricle, $D$-malposition of the great arteries; $A o$, aorta; $A S$, aortic stenosis; $C C A V C$, complete common atrioventricular canal; $D I L V$, double-inlet left ventricle; $D O R V$, doubleoutlet right ventricle; $H L H S$, hypoplastic left heart syndrome; $I A A$, interrupted aortic arch; $L A V V$, left atrioventricular valve; $L S V C$, left superior vena cava; $L V$, left ventricle; $M A$, mitral atresia; $P A$, pulmonary atresia; $P S$ pulmonic stenosis; $R A V V$, right atrioventricular valve; $R V$, right ventricle; $\{S, D, D\}$, same as $\{\mathrm{A}, \mathrm{D}, \mathrm{D}\}$ except situs solitus of the atria; $\{S, D, L\}$, same as $\{$ S,D,D $\}$ except L-malposition of the great arteries; SI-Vent, superoinferior ventricles; $\{S, L, D\}$, same as $\{\mathrm{S}, \mathrm{D}, \mathrm{D}\}$ except L-loop ventricles; $\{S, L, L\}$, situs solitus of the atria, L-loop ventricles, L-malposition of the great arteries; $\{S, L, X\}$, same as $\{S, L, L\}$ except the ventricular-arterial alignment cannot be determined; $T A P V C$, total anomalous pulmonary venous connection; $T G A$, transposition of the great arteries; $T V$, tricuspid valve; $V S D$, ventricular septal defect.

acquisition: effective repetition time $(\mathrm{TR})=50 \mathrm{msec}$, echo time $(\mathrm{TE})=8 \mathrm{msec}$, number of excitations $(\mathrm{NEX})=$ 1 , matrix size $=128 \times 128$, slice thickness $=5$ to $10 \mathrm{~mm}$, and field of view range $=180$ to $250 \mathrm{~mm}$ (mean $=200$ $\mathrm{mm}$ ); receiver bandwidth $=49.92 \mathrm{KHz}$.

Bolus tagging has been extensively validated ${ }^{17-19}$ and directly visualizes the velocity profile, although it yields information in one plane. Further, bolus images on our SP-63 device can be constructed in a short time (advantageous, because six sets of images were needed). Phaseencoded velocity mapping provides flow profile in cross section, but it does not directly visualize it and takes four times as long to construct images (on our SP-63 device). Nevertheless, we performed cardiac triggered bolus tagging and velocity mapping at the same level on the same patient (Fig. 1C), and the results are similar. 

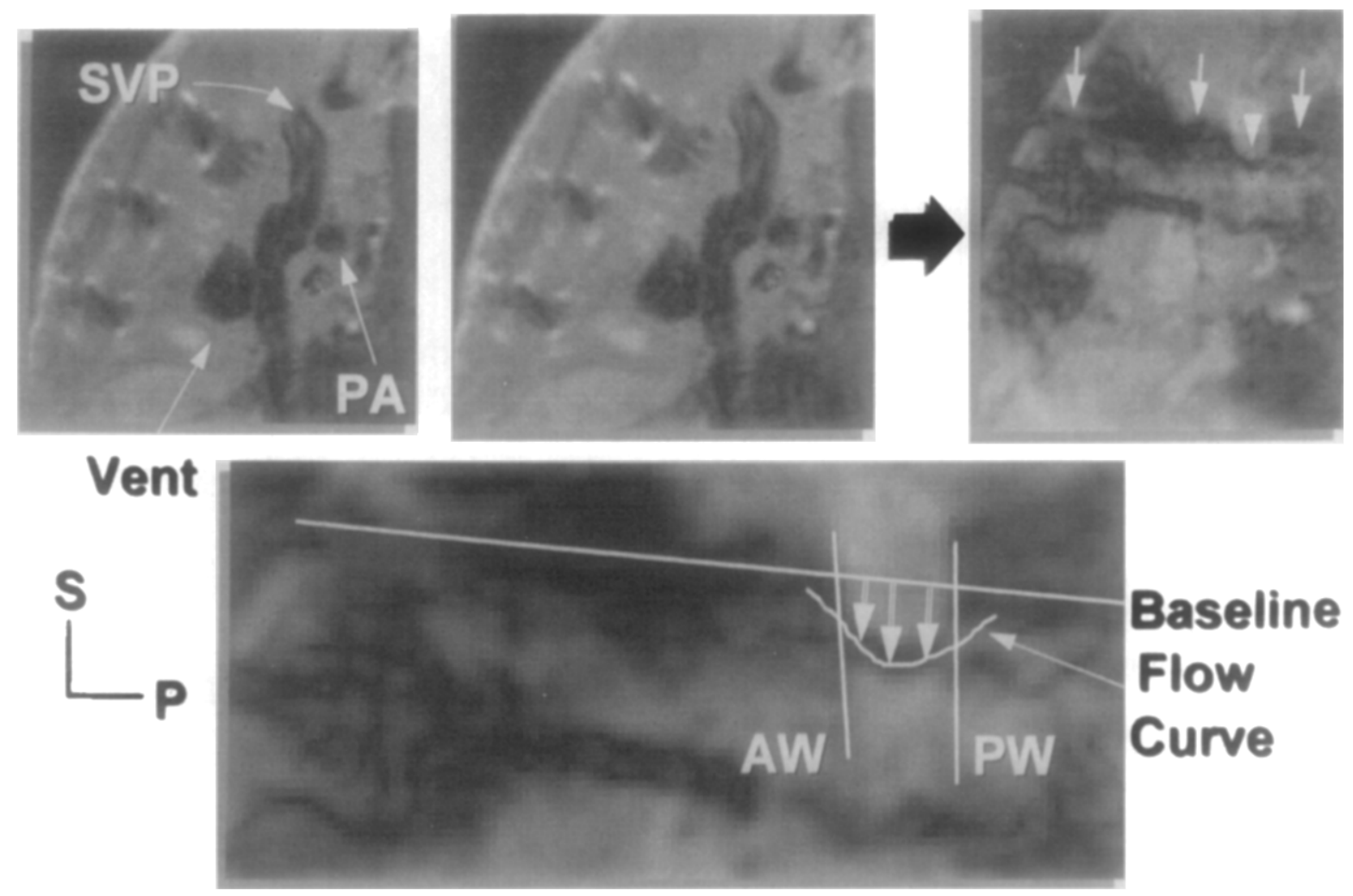

Fig. 1A. MRI protocol to obtain a bolus tag image. Spin-echo images are obtained parallel to blood flow in the SVP (upper left and upper center panels). Saturated spins along a single plane produced a tag that was placed in the SVP just above the IVC-RA junction (not shown), in mid-baffle (not shown), and in the SVC (upper right panel). The movement of blood displaces the saturation band laid down across the vessel (arrowheads), whereas stationary structures such as the chest wall and spine (arrows) maintain the saturation band laid down at its original position. The lower panel depicts image analysis (image is magnified). Both the upper right panel and lower panel are respiratory gated images. Each image is analyzed by tracing both the anterior wall $(A W)$ and posterior wall $(P W)$ of the vessel, the stripe where the tag was laid down (baseline), and the stripe that was moved by the motion of the blood (flow curve) as shown on the right panel. At twelve equally spaced points across the diameter of the vessel, we calculated the path of the blood from the initial position of tagging to the point where blood moved the tag (the lower panel shows only three positions for simplicity, represented by arrows with split tails). $P$, Posterior; $P A$, pulmonary artery; $S$, superior; Vent, ventricle.

Both cardiac (ECG) triggered images (multiple images across the cardiac cycle) and respiratory gated images (an image at end-inspiration and at end-expiration) were obtained. End-inspiratory and end-expiratory images were chosen because they correlate with maximum and minimum respiratory dependent flow, respectively.

For ECG-triggered images, phase encoding occurred 17 msec after the tag and frequency encoding occurred 20 msec after the tag. Tags were created at $50 \mathrm{msec}$ intervals $(\mathrm{TR}=50 \mathrm{msec}$ ) starting $1.2 \mathrm{msec}$ after the $\mathrm{R}$ wave (Fig. $1 B$ ) and were acquired across the cardiac cycle from $R$ wave to within $30 \mathrm{msec}$ of the next $\mathrm{R}$ wave (covering atrial systole).
For respiratory gated studies (Fig. 1A), images were acquired at greater than $90 \%$ maximum bellows expansion (end-inspiration) and at less than $10 \%$ maximum bellows contraction (end-expiration).

Tags ( $2 \mathrm{~mm}$ in diameter) were created just above the IVC-right atrial junction (IVC-RA), in the midportion of the baffle three fourths of the distance from the IVC-RA and the pulmonary artery (mid-baffle), and in the SVC (Figs. 1A and 1B). Tag width and image quality did not vary with imaging type.

Image and data analysis. Images were analyzed on a Sun SPARC 10 workstation (Sun Microsystems) using the Volumetric Image Display and Analysis software 

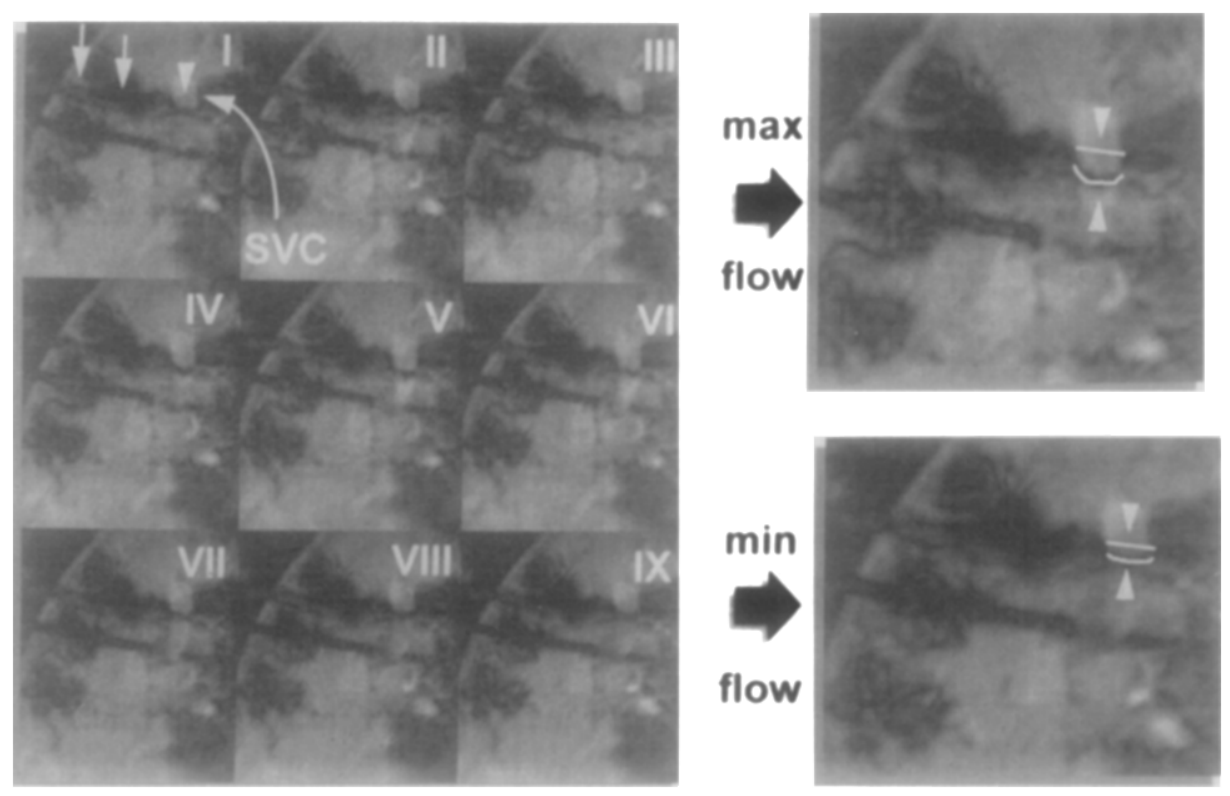

Fig. 1B. Bolus tagging in the SVP. The nine-panel image on the left displays flow in the SVC at $50 \mathrm{msec}$ intervals throughout the cardiac cycle. Note that the tag over the SVC (arrowhead) persists and moves on all nine images. Arrows display where the tag is initially laid down. The panels on the right are magnifications of the SVC at maximum (max) flow (upper panel) and minimum (min) flow (lower panel). Arrowheads and white lines outline the baseline and flow curve.

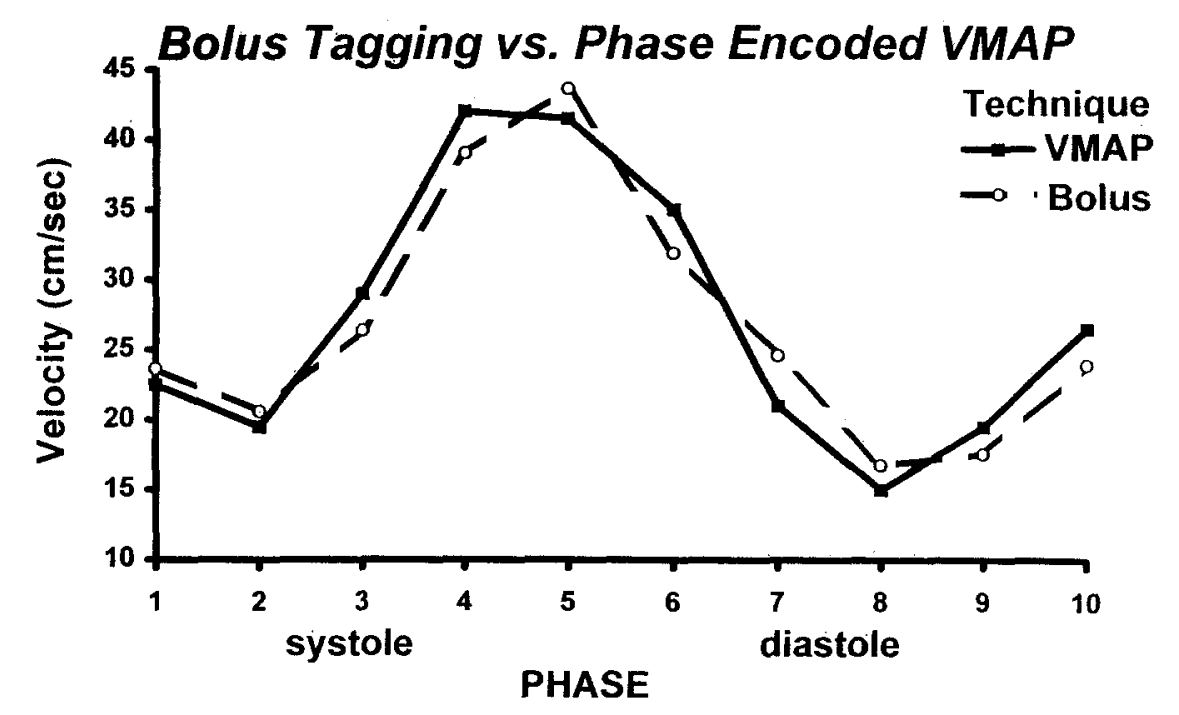

Fig. 1C. A comparison of bolus tagging versus phase-encoded velocity mapping (VMAP). Velocity is plotted on the $Y$ axis and phase of the cardiac cycle is plotted on the $X$ axis $(1=$ beginning, $10=$ end of the R-R interval). Both curves were generated at the same tagging level in the same patient within 5 minutes of each other. Note that the curves are almost superimposable.

package. ${ }^{20}$ On each image, the following features were traced (Figs. 1A and 1B): (1) SVP anterior and posterior walls, (2) the original site of tag placement (baseline), and (3) the position of the tag moved by blood flow (flow curve). Computer-aided enhancement chose the center of the saturation band by finding the local pixel of least intensity. Twelve streamlines were calculated at equally spaced points across the SVP diameter from the weighted averages of the anterior and posterior walls. 
The distance moved along each streamline by the tagged blood was measured and velocity was calculated by means of the following equations (Fig. 1A):

$$
\text { Velocity }(\mathrm{cm} / \mathrm{sec})=\frac{\begin{array}{c}
\text { Distance traveled by } \\
\operatorname{tag}(\mathrm{cm})
\end{array}}{0.02 \mathrm{sec}}
$$

To determine flow, we analyzed the area between flow curve and baseline in the vessel by planimetry; rotating this area 180 degrees around its center yielded the volume of blood crossing the saturation plane at the time of image acquisition (assumes the SVP is circular in cross-section $^{21}$ ). The formula used was as follows:

$$
\begin{gathered}
\text { Volume }(\mathrm{ml})=\sum_{\mathrm{i}}^{\begin{array}{c}
\text { Entire radius } \\
\text { of the vessel }
\end{array}}\left(\left(\frac{\mathrm{D}_{i}^{(c m)}+\mathrm{D}_{i+1}{ }^{(\mathrm{cm})}}{2}\right) \times\right) \\
\left.\frac{\text { Vessel }_{\mathrm{dia}}{ }^{(\mathrm{cm})}}{22} \times \pi \times\left(\frac{\mathrm{R}_{i}^{(c m)+} \mathrm{R}_{i+1}{ }^{(c m)}}{2}\right)\right)(\mathrm{Eq})
\end{gathered}
$$

where $D_{i}$ and $D_{i+1}$ are distances the flow curve has moved at positions $\mathrm{i}$ and $\mathrm{i}+1$, vesse $\mathrm{I}_{\text {dia }}$ is the vessel diameter, and $\mathrm{R}_{\mathrm{i}}$ and $\mathrm{R}_{\mathrm{i}+1}$ are the distance from the center of the vessel at positions $i$ and $i+1$. Flow is calculated by the following equation:

$$
\text { Flow }(\mathrm{ml} / \mathrm{sec})=\frac{\text { Volume }(\mathrm{ml})}{0.02 \mathrm{sec}}
$$

The phase of the cardiac cycle was standardized as a percentage of the cardiac cycle from $R$ wave to $R$ wave. The position across the SVP diameter was standardized as percentage from posterior to anterior wall.

Parameters defined. Inasmuch as all data comparisons were paired measurements, indexing to body surface area was not performed.

Velocity data for cardiac triggered images. For each phase, the greatest velocity of any streamline was determined and maximum and minimum velocity were the highest and lowest of these values, respectively, for any phase. The phase at which maximum and minimum velocity occurred, as well as its position across the SVP, was also calculated. As a measure of how much the velocity profile mirrored "plug flow," the standard deviation of all velocities across the SVP at each phase was computed (i.e., the lower the standard deviation, the more "flat" it was). The largest and smallest standard deviations, as well as the phase at which these velocities occurred, was then determined.

Flow data for cardiac triggered images. For each phase, the flow rate was computed and the average, maximum, and minimum of these values were determined. The phase at which these occurred was also determined.

Respiratory data. End-inspiratory and end-expiratory data included maximum, average, and standard deviation of velocities of any streamline, the position of maximum velocity, and flow.

Flow dependency. If flow were solely respiratory controlled, it would be expected that a cardiac triggered study would demonstrate similar images at all phases. This did not occur. Similarly, if flow were solely cardiac controlled, then it would be expected that a respiratory gated study would demonstrate similar images at end-inspiration and end-expiration. Again, this did not occur. Because cardiac and respiratory cycles occur at the same time, flow dependency was defined as the percentage change in flow during the cardiac cycle (or respiratory cycle) as a fraction of the sum of flow changes noted during both cardiac triggering and respiratory gating. Thus:

$\%$ Cardiac dependency

$$
=\frac{\text { Max flow } \text { card }_{\text {card }}-\text { Min flow }}{\text { card }}
$$

\%Respiratory dependency

$$
=\frac{\text { Flow }_{\text {insp }}-\text { Flow }_{\text {exp }}}{\left(\text { Max }_{\text {flow }} \text { card }- \text { Min flow }_{\text {card }}\right)+}
$$

where max flow card $_{\text {and }}$ min flow card $_{\text {are maximum and }}$ minimum flows as calculated on the cardiac triggered images and flow insp $_{\text {and flow }}$ are flows calculated at end-inspiration and end-expiration.

Statistics. The two-way paired Student's $t$ test was used to determine differences between means in a given patient, and the unpaired Student's $t$ test was used to compare means in unpaired populations. The one-way analysis of variance was used when more than two means were compared, and differences between means were noted with the use of the Scheffe F test. Differences were considered to be significant at $p<0.05$. Statistics were performed on a PC by means of JMP version 3.1.4 for Windows (SAS Institute, Inc., Cary, N.C.). Interobserver variability was determined by the Pearson correlation. All values are mean \pm standard deviation.

\section{Results}

So that interobserver variability for tracking the tag could be tested, all tagging levels in 15 of the 22 patients were tracked by two observers. An excellent interobserver correlation was found $(r=0.97)$ for all streamlines.

SVP: Turbulent versus nonturbulent flow (Figs. $1 \mathrm{~A}$ and $1 \mathrm{~B}$ ). The physics of MRI dictate that when turbulent blood flow occurs in gradient echo imaging, a loss of signal will occur in the region of turbulence. In bolus tagging, this translates into the tag breaking up and the appearance of a signal void. All 22 patients at the three levels displayed persistence of the tag through the cardiac and respiratory cycles, implying laminar flow in the pathway.

SVP: Cardiac and respiratory dependency. Table II expresses the cardiac and respiratory dependency of flow in the SVP. Cardiac dependency predominates, accounting for $69 \%$ to $72 \%$ of the flow. 

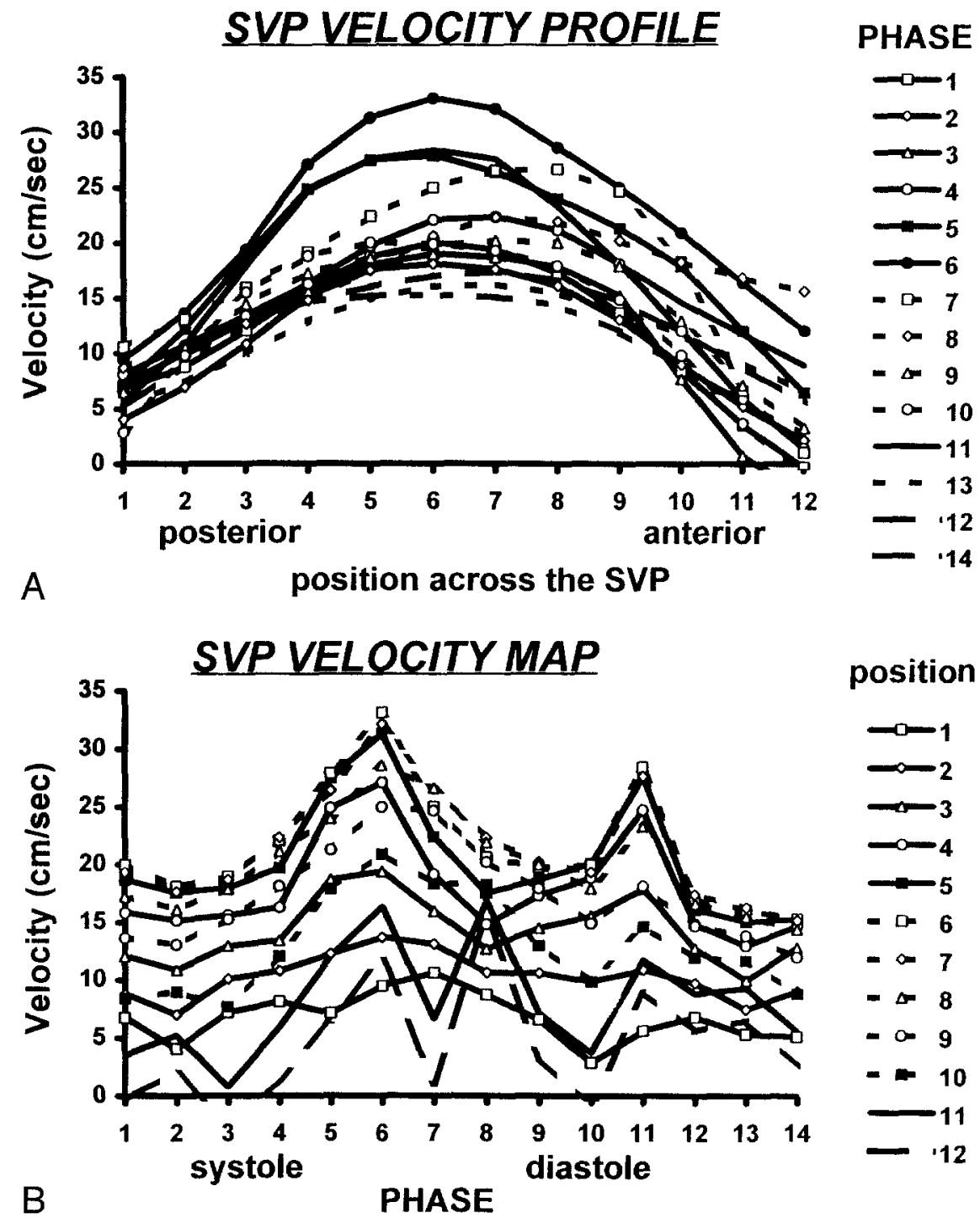

Fig. 2. Bolus tagging and flow in the SVP. A, This figure is representative of data from one patient of the geometry of the velocity profile. This graph of velocity versus position across the SVP displays the velocity profile at all phases of the cardiac cycle (each curve represents a different phase of the cardiac cycle, with $1=$ at $\mathrm{R}$ wave and 14 = just before the next $\mathrm{R}$ wave). $\mathbf{B}$, This figure is representative of data from one patient, which graphs velocity versus time (from $R$ wave to $R$ wave). The family of curves represent the twelve positions across the SVP diameter that were measured, with $1=$ most posterior and $12=$ most anterior.

ECG-triggered SVP flow-velocity profile and flow characteristics (Figs. 1 and 2, Table IIIA). Midbaffle levels demonstrated statistically higher maximum velocity than either IVC-RA or SVC levels, and at all levels, maximum velocity differed significantly from minimum velocity (i.e., velocities were not constant over the cardiac cycle). Maximum velocity occurred in the second quarter of the cardiac cycle and did not differ between tagging levels,
Table II. Cardiac and respiratory dependence

\begin{tabular}{lccc}
\multicolumn{1}{c}{ Factor } & IVC-RA & Mid-baffle & $\overline{\text { SVC }}$ \\
\hline Cardiac (\%) & $70 \pm 15^{*}$ & $69 \pm 22 \dagger$ & $72 \pm 17 \uparrow$ \\
Respiratory (\%) & $30 \pm 15^{*}$ & $31 \pm 22 \dagger$ & $28 \pm 17 \ddagger$ \\
$p$ Value & 0.001 & 0.002 & 0.001 \\
\hline
\end{tabular}

$\overline{I V C-R A}$, The tag position just above the right atrial-inferior vena cava junction; mid-baffle, the tag position in the middle of the systemic venous pathway baffe; $S V C$, the tag position in the superior vena cava.

*f At all three tagging levels, cardiac flow was significantly higher than respiratory flow. 
Table IIIA. Velocity profile characteristics in the SVP triggered to the cardiac cycle

\begin{tabular}{llll}
\hline \multicolumn{1}{c}{ Velocity profile parameter } & IVC-RA & Mid-baffle & SVC \\
\hline Maximum velocity (cm/sec) & $34 \pm 8^{* \dagger}$ & $45 \pm 17^{* \dagger}$ & $35 \pm 11^{* \dagger}$ \\
Phase of maximum velocity (\% of cardiac cycle) & $32 \pm 20 \dagger$ & $41 \pm 21+$ & $43 \pm 14 \ddagger$ \\
Minimum velocity (cm/sec) & $14 \pm 6 \dagger$ & $16 \pm 11 \dagger$ & $17 \pm 6 \dagger$ \\
Phase of minimum velocity (\% of cardiac cycle) & $64 \pm 22 \ddagger$ & $62 \pm 25 \ddagger$ & $60 \pm 29 \ddagger$ \\
Position of maximum velocity (\% from posterior wall) & $48 \pm 20$ & $51 \pm 25$ & $53 \pm 18$ \\
Maximum standard deviation (cm/sec) & $8.8 \pm 3.0 \S$ & $13.4 \pm 8.1 \S$ & $8.9 \pm 3.2 \S$ \\
Minimum standard deviation (cm/sec) & $2.5 \pm 1.6$ & $3.8 \pm 4.1$ & $3.9 \pm 1.9$ \\
Phase of maximum standard deviation (\% of cardiac cycle) & $46 \pm 36$ & $38 \pm 33$ & $44 \pm 34$ \\
Phase of minimum standard deviation (\% of cardiac cycle) & $54 \pm 32$ & $61 \pm 32$ & $50 \pm 39$
\end{tabular}

IVC-RA, The tag position just above the right atrial-inferior vena cava junction; mid-baffle, the tag position in the middle of the systemic venous pathway baffle; phase, measured as a percent of the cardiac cycle from $\mathrm{R}$ wave to $\mathrm{R}$ wave; position, measured as a percent from the posterior wall in relation to the vessel diameter; $S V C$, the tag position in the superior vena cava.

* Mid-baffe demonstrated statistically higher maximum velocity than either the IVC-RA or the SVC $(p=0.04)$

$\dagger$ At all three levels, maximum velocity differed significantly from the minimum velocity ( $p=0.001$ at each level)

$\$$ The phase of minimum velocity differed significantly from the phase of maximum velocity at all tagging levels ( $p=0.002$ at each level).

\$ The highest standard deviation of velocities occurred at mid-baffle and was significantly different from either the IVC-RA or the SVC $(p=0.02)$.

although they did differ from the phase of minimum velocity (third quarter of the cardiac cycle). Position of maximum velocity was in the center of the vessel and did not differ between levels (Figs. 1B and 2A).

When comparing tagging levels, we found that the greatest standard deviation of velocities (the "thickness" of the family of curves on Fig. 2B) occurred at mid-baffle. At all levels, maximum standard deviation occurred during the second quarter of the cardiac cycle (coinciding with the phase of maximum velocity) and the minimum standard deviation occurred in the third quarter of the cardiac cycle (coinciding with phase of minimum velocity).

Flow (Table IIIB) was continuous throughout the cardiac cycle (i.e., flow $\neq 0$, Fig. $1 B$ ). Maximum flow was significantly higher at IVC-RA than at SVC. Further, average flow was statistically higher at IVC-RA and mid-baffle than at SVC. Maximum flow occurred in the second quarter of the cardiac cycle. Minimum flow, however, occurred at the third quarter of the cardiac cycle.

SVP flow gated to the respiratory cycle: Velocity profile and flow characteristics (Fig. 1A, Table IV). No ghosting artifacts were visualized. At mid-baffle, maximum and average velocities during inspiration were significantly higher than at expiration. Further, mid-baffle displayed the highest standard deviation at either phase of the respiratory cycle.

Flow at inspiration was higher than at expiration at all levels, but the difference was significant only at midbaffle. Flow was significantly higher at IVC-RA and mid-baffle than at SVC for any phase of respiration.

\section{Discussion}

Previous studies of the mechanism of pulmonary blood flow in Fontan physiology ${ }^{1-14}$ have implicated cardiac and respiratory factors; however, the degree each contributes and which cardiac events determine this flow are topics of debate. ${ }^{1-11}$ Inspiration $^{2,3,12-14}$ and various phases of the cardiac cycle (atrial contraction, ${ }^{5,7,8}$ ventricular systole, $, 1,2,4,5,7-9$ and ventricular diastole ${ }^{1,8,9,11}$ ) are thought to play major roles in determining this flow.

The ultimate shape of the velocity profile is dependent on a complex set of interactions. Determining this shape has far-reaching implications for shear forces and energetics, ${ }^{22-24}$ correct interpretation of Doppler data, ${ }^{25,26}$ thrombus formation, ${ }^{27}$ and for the understanding of the circulation's fluid mechanics. ${ }^{22-27}$ Also, as mentioned earlier, the velocity profile is directly relevant to the problems faced in Fontan physiology. ${ }^{28,29}$ It is a function of many factors including Poiseuille's law, the Reynolds number, the entrance length for fully developed flow, the pulsatile nature of flow, and the vessel geometry. ${ }^{23,24}$ This, in turn, determines the hydraulic energies needed to propel blood, which should ideally be optimized in the SVP of patients having the Fontan operation. Some of these factors may be controlled during surgical creation of the SVP or manipulated by medication.

No large series have studied the total cavopulmonary connection flow dynamics in vivo and separated it into respiratory and cardiac components. The importance to this study lies in the realization that 
Table IIIB. Flow characteristics in the SVP triggered to the cardiac cycle

\begin{tabular}{llll}
\multicolumn{1}{c}{ Flow parameters } & NVC-RA & Mid-Baffle & SVC \\
\hline Maximum flow (ml/sec) & $77 \pm 78^{*} \dagger$ & $69 \pm 91 \dagger$ & $44 \pm 50^{*} \dagger$ \\
Minimum flow (ml/sec) & $30 \pm 31^{* \dagger}$ & $27 \pm 5 \dagger$ & $18 \pm 22^{*} \dagger$ \\
Average flow (ml/sec) & $50 \pm 48 \dagger$ & $52 \pm 34 \ddagger$ & $31 \pm 36 \ddagger$ \\
Phase of maximum flow (\% of cardiac cycle) & $28 \pm 31 \S$ & $47 \pm 35$ & $47 \pm 21 \S$ \\
Phase of minimum flow (\% of cardiac cycle) & $66 \pm 27 \S$ & $52 \pm 34$ & $64 \pm 38 \S$ \\
\hline
\end{tabular}

IVC-RA, The tag position just above the right atrial-inferior vena cava junction; mid-baffe, the tag position in the middle of the systemic venous pathway baffle; cardiac cycle; phase, measured as a percent of the cardiac cycle from $\mathrm{R}$ wave to $\mathrm{R}$ wave; total (over whole cardiac cycle); SVC, the tag position in the superior vena cava.

* Maximum and minimum flow rates at the IVC-RA were higher than at SVC $(p=0.001$ and $p=0.03$, respectively).

$\uparrow$ Maximum flow rate was higher than minimum flow rate at all three tagging levels ( $p=0.001, p=0.003$, and $p=0.009$ for IVC-RA, mid-baffle and SVC, respectively).

\$ Average flow rate was higher at the IVC-RA and mid-baffle than at SVC $(p=0.01)$.

$\S$ Phase at maximum flow was earlier than phase at minimum flow ( $p=0.005$ and $p=0.02$ for IVC-RA and SVC, respectively).

SVP geometry, as well as the materials used to construct the SVP, can be altered to create a more optimal flow pattern. Localizing the cardiac phase in which the most flow occurs allows medications to be targeted to enhance this phase, which will have a favorable impact on the "passive" flow into the lungs.

SVP: Turbulent versus nonturbulent flow. de Leval and associates ${ }^{15}$ have suggested that forming the SVP in the Fontan reconstruction as a cylindric tube minimizes energy losses and creates a uniform flow pattern. Our study confirms, in vivo, that chaotic flow is not present in the SVP and that the flow is nearly uniform in this type of Fontan connection.

SVP: Cardiac and respiratory dependence. Clearly, the dependence of pulmonary blood flow in Fontan physiology is not wholly respiratory, because a patient receiving positive-pressure ventilation while supported by a respirator would not survive the Fontan operation. Pulmonary blood flow is also clearly not wholly cardiac dependent. ${ }^{3,12-14}$ Part of the problem stems from how to define "cardiac" and "respiratory" dependency. We believe that by defining flow dependency as in our study, we have a useful definition from which we may draw reasonable conclusions about the nature of the flow.

Our findings demonstrate that flow is predominantly dependent on cardiac events. In fact, our calculations of cardiac dependency are conservative inasmuch as we did not account for the approximately 4:1 difference in heart and respiratory rates. To treat the patient who has had a Fontan operation by optimizing pulmonary blood flow, we believe ventricular diastole should be augmented.

A significant amount of flow was noted to occur during ventricular systole. Nakazawa, ${ }^{7}$ DiSessa,${ }^{9}$ and their associates suggested that atrial relaxation may contribute to this. Qureshi and colleagues ${ }^{5}$ demonstrated that pulsatile flow occurred during ventricular systole, implying an "active" mechanism. Frommelt and coworkers ${ }^{1}$ noted a correlation of pulmonary artery flow with biphasic left atrial pressure, suggesting both an active and passive mechanism. Hagler's group ${ }^{8}$ found a significant amount of flow in late systole and early diastole, and Giannico and coworkers ${ }^{2}$ demonstrated systolic forward flow (although less than diastolic forward flow), but neither speculated on the mechanism.

Both passive and active mechanisms are plausible in explaining the forward systolic flow that we demonstrated. Note that the mid-baffle level had a greater velocity and standard deviation of velocities than other levels. Because this is intracardiac, we may be visualizing an effect of the atrioventricular valve plane motion on the noncompliant polytetrafluoroethylene material (so-called "suction" effect) directly, or the effect may be a function of polytetrafluoroethylene material making up the SVP.

SVP velocity profiles and flow characteristics. A significant step-up in maximum velocity from IVC-RA to mid-baffle level in cardiac triggered images and during inspiration was noted. This step-up may represent a cardiac or respiratory dependent change in the SVP diameter at that level or may have to do with the geometry of flow at this level, which is close to where blood from the IVC-RA and SVC meet to enter the pulmonary artery. In either case, this represents a different flow phenomenon than at the IVC-RA and SVC and may be important in energy losses.

Maximum velocity and flow occurred during the second quarter of the cardiac cycle, coinciding with late systole and early diastole. This is consistent with the early diastolic filling phase determining pulmo- 
Table IV. Velocity profile and flow characteristics in the SVP gated to the respiratory cycle

\begin{tabular}{|c|c|c|c|}
\hline & $I V C-R A$ & Mid-baffle & $S V C$ \\
\hline \multicolumn{4}{|l|}{ Velocity profile parameter } \\
\hline Maximum velocity during expiration $(\mathrm{cm} / \mathrm{sec})$ & $26 \pm 11$ & $26 \pm 11$ & $23 \pm 8$ \\
\hline Maximum velocity during inspiration $(\mathrm{cm} / \mathrm{sec})$ & $27 \pm 11$ & $32 \pm 11 \|$ & $26 \pm 10$ \\
\hline Average velocity during expiration $(\mathrm{cm} / \mathrm{sec})$ & $18 \pm 9$ & $15 \pm 6$ & $17 \pm 5$ \\
\hline Average velocity during inspiration $(\mathrm{cm} / \mathrm{sec})$ & $18 \pm 6$ & $21 \pm 8 \mid$ & $19 \pm 7$ \\
\hline Position of maximum velocity during expiration ( $\%$ from posterior wall) & $52 \pm 25^{*}$ & $51 \pm 17^{*}$ & $39 \pm 20^{*}$ \\
\hline Position of maximum velocity during inspiration ( $\%$ from posterior wall) & $48 \pm 30^{*}$ & $57 \pm 23^{*}$ & $43 \pm 15^{*}$ \\
\hline Standard deviation of velocities during expiration $(\mathrm{cm} / \mathrm{sec})$ & $6.4 \pm 5.0 \dagger$ & $7.8 \pm 4.1 \dagger$ & $5.1 \pm 2.5 \dagger$ \\
\hline Standard deviation of velocities during inspiration $(\mathrm{cm} / \mathrm{sec})$ & $6.8 \pm 4.2 \dagger$ & $8.7 \pm 5.8 \dagger$ & $5.4 \pm 3.5 \dagger$ \\
\hline \multicolumn{4}{|l|}{ Flow parameters } \\
\hline Flow during expiration $(\mathrm{ml} / \mathrm{sec})$ & $58 \pm 55 \S$ & $39 \pm 44+8$ & $24 \pm 17 \S$ \\
\hline Flow during inspiration $(\mathrm{ml} / \mathrm{sec})$ & $66 \pm 64 \S$ & $57 \pm 50 \pm 8$ & $29 \pm 28 \S$ \\
\hline
\end{tabular}

$I V C-R A$, The tag position just above the right atrial-inferior vena cava junction; mid-baffle, the tag position in the middle of the systemic venous pathway baffle; $\min$, minimum; $S V C$, the tag position in the superior vena cava.

* Position of maximum velocity was more posterior in the SVC than other tagging levels at either inspiration $(p=0.04)$ or expiration $(p=0.05)$. $\uparrow$ Mid-baffle demonstrated the highest standard deviation of all tagging levels at either phase of respiration ( $p=0.05$ for either phase of respiration). \# Flow at inspiration was higher than at expiration at all three tagging levels, but reached statistical significance only at mid-baffle $(p=0.05)$. $\S$ Flow in the IVC-RA and mid-baffle were higher than at SVC during respiration $(p=0.04)$.

\| Maximum and average velocity at mid-baffle were statistically greater than at other levels ( $p=0.05$ for both maximum and average velocities).

nary blood flow. $1,2,8,9,11$ Minimum velocity and flow occurred in the third quarter of the cardiac cycle, coinciding with diastasis, when pulmonary venous flow is the slowest and diastolic compliance is the lowest. ${ }^{30}$

The position of maximum velocity was in the center of the SVP at all levels, which agrees with theories of flow in Newtonian fluids. ${ }^{23,24} \mathrm{We}$ also demonstrated that greatest maximum velocity was at the mid-baffle level, where the greatest standard deviation of velocities (lowest degree of "plug" flow) occurred, implying that increased velocity occurs during the highest amount of disordered flow. Midbaffle flow may be less "pluglike" than other levels because (1) flow is moving faster, (2) it is close to the intersection point of flow from SVC to pulmonary artery, (3) it is in the middle of the atria where cardiac motion effects may be more pronounced, or (4) there is synthetic material at this level, causing more disordered flow.

Flow at inspiration was noted to be higher than at expiration at all levels. This is consistent with the notion that an increase in negative intrathoracic pressure acts as a "suction," pulling more blood into the pulmonary circuit than during expiration.

Limitations. Our temporal resolution was 50 $\mathrm{msec}(20 \mathrm{~Hz})$ for the cardiac triggered images, and we gated to only the top $10 \%$ of inspiration and the bottom $10 \%$ of expiration. Any flow-related events occurring quicker than that would not be imaged. Furthermore, if any flow-related events took place between tagging levels, we would also not have a full spatial description of the flow. We doubt that this has substantially affected our results or conclusions.

The SVP may move with respiration. In our experience by MRI and echocardiography, this does not appear to be the case. What little motion there is appears in the superoinferior dimension, even less in the anteroposterior plane, and none in the lateral plane. In sagittal imaging, only lateral motion would move the imaging plane away from the vessel center.

Evaluation of late atrial systole by means of $\mathrm{R}$-wave triggering in patients with heart rate variability may have been a problem because of "gating overruns." Inasmuch as each acquisition took slightly more than 1 minute, there was little time for the heart rate to vary greatly. Sedation also kept heart rate variability to a minimum. We found no image degradation with the little "gating overruns" that did occur.

Our spatial resolution was approximately $0.8 \mathrm{~mm}$, using a $128 \times 128$ matrix, field of view $=200 \mathrm{~mm}$, and conservatively estimating subpixel tag tracking at 0.5 pixel. For velocities of 35 to $45 \mathrm{~cm} / \mathrm{sec}$, this yields an error of $8 \%$ to $10 \%$. This assumes that the limits of accuracy of a band " $\mathrm{X}$ " mm wide is less than or equal to "X/2" mm. In addition, we acknowledge that pixels do not have a rectangular impulse response, making the saturation band edges not as sharp in theory. We would also expect that if the error rate in tracking the tag was too high, there would be a lot of noise in the velocity profile, which was not observed (Figs. 1A and 1B and Fig. 2). 
Therefore, it appears unlikely that this has substantially affected our results or conclusions.

\section{Conclusion}

A substantial amount of flow into the lungs in patients who have undergone a total cavopulmonary connection type of Fontan operation has a cardiac component. Furthermore, we confirm that this flow is laminar but nonuniform across the SVP. Highest flows occurred near end-systole and early diastole, as well as in inspiration, and the lowest flow occurred in diastasis. The flow at the mid-baffle level was least like "plug" flow and may be a significant flow phenomenon. This information may help in designing the SVP and optimizing medical management.

We thank Brent Baxter, MS, and John Hoford, BS, for their support.

\section{REFERENCES}

1. Frommelt PC, Snider AR, Meliones JN, Vermilion RP. Doppler assessment of pulmonary artery flow patterns and ventricular function after the Fontan operation. Am J Cardiol 1991;68:1211-5.

2. Giannico S, Corno A, Marino B, Cicini MP, Gagliardi MG, Amodeo $\mathrm{A}$, et al. Total extracardiac right heart bypass. Circulation 1992;86(Suppl):II110-7.

3. Penny DJ, Redington AN. Doppler echocardiographic evaluation of pulmonary blood flow after the Fontan operation: the role of the lungs. Br Heart J 1991;66:372-4.

4. Fontan F, Kirklin JW, Fernandez G, Costa F, Naftel DC, Tritto F, et al. Outcome after a "perfect" Fontan. Circulation 1990;81:1520-36.

5. Qureshi SA, Richheimer R, McKay R, Arnold R. Doppler echocardiographic evaluation of pulmonary artery flow after modified Fontan procedure: importance of atrial contraction. Br Heart J 1990;64:272-6.

6. Laks H, Milliken JC, Perloff JK, Hellenbrand WE, George BL, Chin A, et al. Experience with the Fontan procedure. J Thorac Cardiovasc Surg 1984:88:939-51.

7. Nakazawa M, Nakanishi T, Okuda H, Santomi G, Nakae S, Imai $\mathrm{Y}$, et al. Dynamics of right heart flow in patients after Fontan procedure. Circulation 1984;69:306-12.

8. Hagler DJ, Seward JB, Tajik AJ, Ritter DG. Functional assessment of the Fontan operation: combined M-mode, two-dimensional and Doppler echocardiographic studies. J Am Coll Cardiol 1984;4:756-64.

9. DiSessa TG, Child JS, Perloff JK, Wu L, Williams RG, Laks $\mathrm{H}$, et al. Systemic venous and pulmonary arterial flow patterns after Fontan's procedure for tricuspid atresia or single ventricle. Circulation 1984;70:898-902.

10. Rebergen SA, Ottenkamp J, Doornbos J, van der Wall EE, Chin JG, de Roos A. Postoperative pulmonary flow dynamics after Fontan surgery: assessment with nuclear magnetic resonance velocity mapping. J Am Coll Cardiol 1993;21:123-31.

11. Chiu IS, Wang JK, Lai JS, Hung CR. Surgical treatment of tricuspid atresia. J Formosan Med Assoc 1991;90:347-52.

12. Lane S, Daubeney P, Walsh K, Dawkins K, Salmon A.
Seizure activity causing loss of cardiac output after a Fontan operation. Arch Dis Child 1995;72:62-3.

13. Penny DJ, Hayek Z, Redington AN. The effects of positive and negative extrathoracic pressure ventilation on pulmonary blood flow after the total cavopulmonary shunt procedure. Int J Cardiol 1991;30:128-30.

14. Redington AN, Penny DJ, Shinebourne EA. Pulmonary blood flow after total cavopulmonary shunt. Br Heart $\mathbf{J}$ 1991;65:213-7.

15. de Leval MR, Kilner P, Gewillig M, Bull C. The total cavopulmonary connection: a logical alternative to atriopulmonary coninection for complex Fontan operations. J Thorac Cardiovasc Surg 1988;96:682-95.

16. Fogel MA, Chin AJ. Imaging of pulmonary venous pathway obstruction in patients after the modified Fontan procedure. J Am Coll Cardiol 1992;20:181-90.

17. Edelman RR, Mattle HP, Kleefield J, Silver MS. Quantification of blood flow with dynamic MR imaging and presaturation bolus tracking. Radiology 1989;171:551-6.

18. Matsuda T, Shimizu K, Sakurai T, Fujita A, Ohara H, Okamura S, et al. Measurement of aortic blood flow with MR imaging: comparative study with Doppler US. Radiology 1987;162:857-61.

19. Hoydu AK. New methodologies for investigating wave propagation and reflection in the aorta. 1st ed. Philadelphia: University of Pennsylvania Press; 1993. p. 203-14.

20. Hoffman EA, Gnanaprakasam D, Gupta KB, Hoford JD, Kugelmass SD, Kulawiec RS. VIDA: An environment for multidimensional image display and analysis. Proceedings of the Society of Photo-Optical Instrumentation Engineers. Bellingham [WA]. 1992;1660:694-711.

21. Chin AJ. Noninvasive imaging of congenital heart disease before and after surgical reconstruction. 1st ed. Armonk (NY): Futura; 1994. p. 349.

22. Seed WA, Wood NB. Velocity patterns in the aorta. Cardiovasc Res 1971;5:319-30.

23. Cape EG, Sung HW, Yoganathan AP. Physics of blood flow. In: Nanda NC, editor. Doppler echocardiography. Philadelphia: Lea \& Febiger; 1993. p. 24-34.

24. Bird RB, Stewart WE, Lightfoot EN. Transport phenomenon. New York: John Wiley; 1960. p. 11-50.

25. Lucas CL, Keagy BA, Hsiao HS, Johnson TA, Henry GW, Wilcox BR. The velocity profile in the canine ascending aorta and its effects on the accuracy of pulsed Doppler determinations of mean blood velocity. Cardiovasc Res 1984;18:282-93.

26. Rossvoll O, Samstad S, Torp HG, Linker DT, Skjaerpe T, Angelsen BA, et al. The velocity distribution in the aortic annulus in normal subjects: a quantitative analysis of twodimensional Doppler flow maps. J Am Soc Echocardiogr 1991;4:367-78.

27. Rieu R, Friggi A, Pellisier R. Velocity distribution along an elastic model of human arterial tree. J Biomech 1985;18:70315.

28. Nir A, Driscoll DJ, Mottram CD, et al. Cardiorespiratory response to exercise after the Fontan operation: a serial study. J Am Coll Cardiol 1993;22:216-20.

29. Jahangiri $M$, Ross DB, Redington AN, Lincoln $C$, Shinebourne EA. Thromboembolism after the Fontan procedure and its modifications. Ann Thorac Surg 1994;58:1409-13:

30. Berne RM, Levy MN. Cardiovascular physiology. 6th ed. St. Louis: Mosby-Year Book; 1992. p. 73. 